\title{
Symptoms and signs in fibromyalgia syndrome
}

\author{
I segni e $i$ sintomi della sindrome fibromialgica
}

\begin{abstract}
G. Cassisi ${ }^{1}$, P. Sarzi-Puttini ${ }^{2}$, A. Alciati ${ }^{3}$, R. Casale ${ }^{4}$, L. Bazzichi ${ }^{5}$, R. Carignola ${ }^{6}$, R.H. Gracely ${ }^{7}$, F. Salaffi ${ }^{8}$ F. Marinangeli ${ }^{9}$, R. Torta ${ }^{10}$, M.A. Giamberardino ${ }^{11}$, D. Buskila ${ }^{12}$, M. Spath ${ }^{13}$, M. Cazzola ${ }^{14}$, M. Di Franco ${ }^{15}$, G. Biasi ${ }^{16}$, S. Stisi ${ }^{17}$, L. Altomonte ${ }^{18}$, G. Arioli1 ${ }^{19}$, G. Leardini ${ }^{20}$, R. Gorla ${ }^{21}$, A. Marsico ${ }^{22}$, F. Ceccherelli23 ${ }^{23}$ F. Atzeni' ${ }^{2}$ (Italian Fibromyalgia Network)

${ }^{I}$ Rheumatology Branch, Specialist Outpatients' Department, Belluno, Italy; ${ }^{2}$ Rheumatology Unit, L.Sacco University Hospital, Milan, Italy; ${ }^{3}$ Department of Psychiatry, L. Sacco University Hospital, Milan, Italy; ${ }^{4}$ Department of Clinical Neurophysiology and Pain Rehabilitation Unit, Foundation Salvatore Maugeri, IRCCS, Scientific Institute of Montescano, Montescano (PV), Italy; ${ }^{5}$ Department of Internal Medicine, Division of Rheumatology, S. Chiara Hospital, University of Pisa, Italy; ${ }^{6}$ S.C.D.U. Internal Medicine I, Department of Clinical and Biological Science, University of Turin, Italy; ${ }^{7}$ Department of Medicine, University of Michigan Health System, Ann Arbor, USA; ${ }^{8}$ Department of Rheumatology, Polytechnic University of the Marche Region, Ancona, Italy; ${ }^{9}$ Department of Anesthesiology and Pain Medicine, L'Aquila University, L'Aquila, Italy; ${ }^{10}$ Department of Neuroscience, University of Turin, A.S.O. San Giovanni Battista of Turin, Turin, Italy; ${ }^{11}$ Ce.S.I. "G. D'Annunzio" Foundation, Department of Medicine and Science of Aging, “G. D'Annunzio”, University of Chieti, Italy; ${ }^{2}$ Department of Medicine H, Soroka Medical Center and Faculty of Health Sciences, Ben Gurion University, Beer Sheva, Israel; ${ }^{13}$ Friedrich-Baur-Institute, University of Munich, Germany; ${ }^{14}$ Unit of Rehabilitative

Medicine "Hospital of Circolo", Saronno (VA), Italy; ${ }^{15}$ Chair of Rheumatology, University la Sapienza Rome, Rome, Italy;

${ }^{16}$ Unit of Rheumatology, University of Siena, Siena, Italy; ${ }^{17}$ Rheumatology Unit, "G. Rummo" Hospital, Benevento, Italy;

${ }^{18}$ UOC of Rheumatology Hospital S. Eugenio, Rome, Italy; ${ }^{19}$ Division of Rehabilitative Medicine and Rheumatology, General Hospital of Pieve di Coriano (Mantua), Italy; ${ }^{20}$ Rheumatology Unit, SS Giovanni e Paolo Hospital, Venice, Italy; ${ }^{21}$ Rheumatology and Clinical Immunology, Spedali Civili and University of Brescia, Italy; ${ }^{22}$ Rheumatology Unit, Hospital of Taranto, Taranto, Italy; ${ }^{23}$ IOV (Veneto Cancer Institute), IRCCS, Department of Pharmacology and Anesthesiology, University of Padua, Italy
\end{abstract}

Competing interests: none declared

\section{RIASSUNTO}

La sindrome fibromialgica (FM) è una comune condizione di dolore cronico che interessa almeno il $2 \%$ della popolazione. Il dolore cronico diffuso è l'elemento caratterizzante la FM, ma i pazienti possono riferire una varietà di altri sintomi, compresi disturbi del sonno, astenia, sindrome da colon irritabile, cefalea, e disturbi del tono dell'umore. L'eziologia della FM non è completamente conosciuta e la sindrome viene influenzata da una varietà di fattori quali stress, malattie mediche e una molteplicità di condizioni dolorose. Stabilire la diagnosi può essere difficile a causa della natura multiforme della sindrome e della sovrapposizione con altre sindromi dolorose croniche. Un'ipotesi unificatrice è che la FM risulti dalla sensibilizzazione del sistema nervoso centrale; questo nuovo concetto potrebbe giustificare la varietà di caratteristiche cliniche della sindrome. I sintomi della FM possono essere muscolo scheletrici, non-muscoloscheletrici o una combinazioni di entrambi e molti pazienti sperimentano un insieme di sintomi o condizioni cliniche. I criteri classificativi ACR si focalizzano solamente sul dolore e non considerano altri sintomi importanti, ma tre sintomi-chiave, dolore, astenia e disturbi del sonno sono presenti praticamente in ogni paziente affetto da FM. Parecchi altri disturbi associati comprendenti i sistemi circolatorio, nervoso, digestivo, e genito-urinatio sono probabilmentre parte della cosiddetta sindrome da sensibilizzazione centrale. Una minoranza dei pazienti (30-40\%) ha un significativo disturbo psicologico. I disturbi psichiatrici più comunemente descritti sono i disturbi del tono dell'umore, ma le patologie psichiatriche non costituiscono un fattore necessario nella eziopatogenesi della FM.

Reumatismo, 2008; 60: Supplemento 1: 15-24

\section{INTRODUCTION}

F ibromyalgia (FM) is currently classified as chronic widespread pain with widespread al-

Corresponding author:

Fabiola Atzeni, MD, PhD

Rheumatology Unit

L. Sacco University Hospital, Milan, Italy

E-mail: atzenifabiola@hotmail.com lodynia/hyperalgesia to pressure pain and is categorized among the large group of soft-tissue pain syndromes. FM remains an elusive condition of unknown etiology in which patients report not only chronic widespread pain but also a variety of other complaints, so that it is one of several relatively common overlapping syndromes characterized by otherwise unexplained chronic pain and fatigue $(1,2)$. 
The cardinal features are chronic widespread pain in the presence of multiple tender points throughout the body on physical examination.

FM, as defined by the American College of Rheumatology (ACR) 1990 definition for clinical trials, is a chronic widespread pain condition with characteristic tender points on physical examination, often associated with a constellation of symptoms such as fatigue, sleep disturbance, headache, irritable bowel syndrome, and mood disorders. The ACR defined 2 major compulsory criteria for classifying FM in adults. The first criterion is a history of widespread pain for at least 3 months. The second criterion requires patient report of tenderness in at least 11 of 18 defined tender points when digitally palpated with about $4 \mathrm{~kg}$ per unit area of force (3).

Diagnosis is on the contrary made by a combination of patient history, physical examination, laboratory evaluations, and exclusion of other causes for symptoms attributed to FM.

It has also been noted that the ACR classification criteria focus only on pain and disregard other important symptoms of FM, including fatigue, cognitive disturbance, sleep disturbance, and psychological distress, and that focusing strictly on pain may fail to capture the "essence" of this syndrome (4). Three key features pain, fatigue and sleep disturbance are present in virtually every patient with FM (5) even if the hallmark symptom that differentiates FM from most other medical conditions is the pronounced tenderness to even mildest palpation or physical touch, i.e. allodynia $(6,7)$.

A recent study provided some evidence of the seriousness of improper diagnosis, criticizing the disturbing diagnostic error rate $(66 \%)(8)$. With regard to this, the principal author of the 1990 ACR Criteria recently published an editorial article entitled "Stop using the ACR Criteria in the Clinic" (9).

In a very recent study, in order to develop a new definition of FM based on symptoms and without tender points, the authors concluded that the key symptoms are chronic widespread pain, nonrestorative sleep and subjective disabilities, implying that FM is more than just a pain disorder (10).

In the late '80s, Yunus proposed that preliminary clinical criteria for FM should include some historical features besides the tender point count, a description of pain as "hurt all over," anxiety and stress, non restorative sleep, fatigue, irritable bowel symptoms, and pain referred by patients in seven sites (11).
Table I - Full OMERACT 8 group responses in percentages (13).

\begin{tabular}{|lccc|}
\hline Domain & A & B & C \\
\hline Pain & 94 & 3 & 3 \\
Fatigue & 86 & 13 & 1 \\
Patient Global & 81 & 12 & 7 \\
Sleep & 64 & 26 & 10 \\
Multidimensional function & 60 & 28 & 12 \\
HRQOL & 52 & 34 & 14 \\
Tenderness & 50 & 27 & 24 \\
Depression & 44 & 34 & 21 \\
Treatment side effects & 40 & 34 & 26 \\
Anxiety & 22 & 43 & 35 \\
Dyscognition & 21 & 42 & 37 \\
Stiffness & 13 & 35 & \\
52 & \multicolumn{4}{|}{} \\
\hline A: essential for core set for all clinical studie. B: necessary but not mandatory for \\
\hline
\end{tabular}

In 1992 a consensus document (the Copenhagen declaration) identified FM is part of a wider syndrome involving headaches, bruxism, irritable bowel, irritable bladder, sleep disorders, dysmenorrhea, depression and anxiety disorders, cold sensitivity, Raynaud's phenomena, restless legs, atypical patterns of numbness and tingling, complaints of weakness, exercise intolerance, cognitive dysfunction, autonomic nervous system or neuroendocrine dysregulation (12).

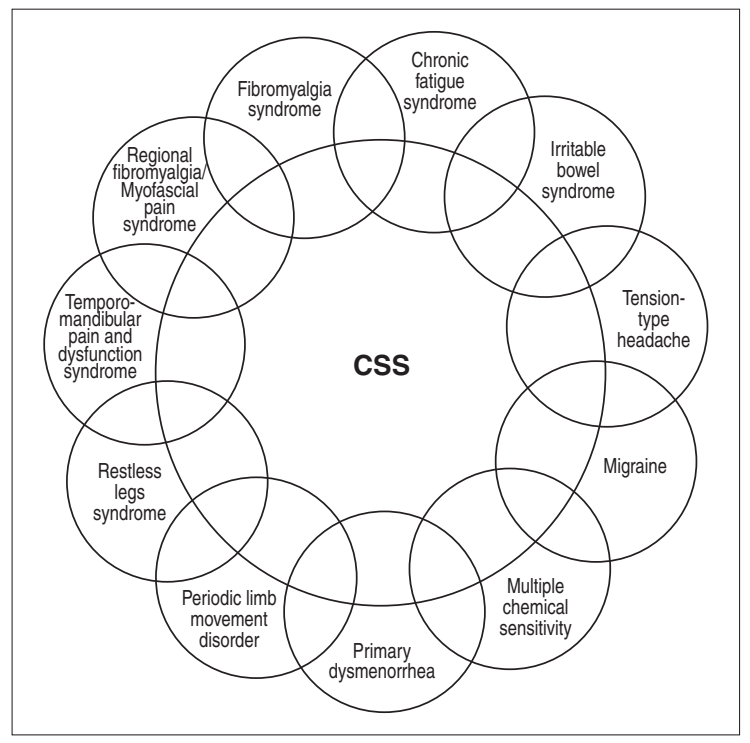

Figure 1 - Central Sensitivity Syndrome and its members with overlapping features. From Yunus MB.Psychological aspects of fibromyalgia syndrome: a component of the dysfunctional spectrum syndrome. Baillieres Clin Rheumatol. 1994; 8(4): 811-37. In Rachlin ES, Rachlin IS. Myofascial Pain and Fibromyalgia, Trigger Point Management. 2nd ed. St. Louis: Mosby, 2002 (adapted). 
OMERACT 8 workshop on FM in 2006, of which the principal objective was to work towards consensus on core domains for assessment in FM studies, identified key domains of pain, fatigue, sleep disturbance, multidimensional function, quality of life, mood disorders, and cognitive dysfunction. An additional domain highlighted by patients was stiffness (13) (Table I). At last we cannot ignore the evolving idea of central sensitivity syndrome (CSS), which is based on neuroendocrine aberrations interacting with psychosocial factors. CSS becomes an important new concept that embraces the biopsychosocial model of disease as a useful paradigm and an appropriate terminology for FM and related conditions $(14,15)$ (Fig. 1).

\section{THE SYMPTOMS}

The most common and characteristic symptoms of FM are generalized pain, stiffness, fatigue, and poor sleep. Other symptoms are a swollen feeling in soft tissue and paresthesia. Several associated illnesses, more common in FM patients than in normal population (as well as in those with other chronic pain conditions) have been well described (16).

\section{MUSCULOSKELETAL SYMPTOMS}

\section{Pain}

As mentioned, the defining symptom of FM remains widespread chronic pain that lasts at least three months, usually present in all four limbs, as well as the upper or lower back. About two thirds of the patients state that they "hurt all over"; this symptom has been found to be useful in differentiating FM from other conditions (11).

Pain may be described as any combination of burning, searing, tingling, shooting, stabbing, deep aching, sharp and feeling bruised all over (17). Some authors, using an adapted McGill Pain Questionnaire, found that pain in FM had a greater spatial distribution and involved a greater number of pain descriptors compared to other pain syndromes (18).

Common sites of pain are low back, neck, shoulder region, arms, hands, knees, hips, thighs, legs, feet (19), and anterior chest (20). However, pain is usually generalized and in "non-anatomical" distribution or regional; it does not follow any definite structural or nerve root distributions, it is perceived as originating in the muscle or deep in bones (17), although in a subgroup of patients it is predominantly articular (21).

Characteristics of FM pain include allodynia, hyperalgesia, persistent pain, summation effects, hyperpatia in the skin and tenderness on examination.

Pain is often aggravated, like stiffness, by cold or humid weather, anxiety or stress, overuse or inactivity, poor sleep $(19,22)$ and noise $(20)$. The worst times for an FM patient are in the morning, the latter half of the afternoon, and evening (23).

\section{Myalgia and muscle dysfunctions}

Pain often includes widespread myalgia that is not necessarily confined to the tender points, and with characteristics that vary widely even in an individual patient. It can also appear as low back pain, sometimes simulating sciatica; in this case there may be a concomitant myofascial pain syndrome (piriformis, gluteus).

Approximately $40 \%$ of FM patients reported leg cramps in comparison to $2 \%$ of controls (24).

Myalgia can be accompanied by muscle weakness and fasciculations with or without general weakness. Muscle function is globally impaired (most of all aerobic processes) (25) and strength is generally reduced in the hand and quadriceps, in particular (26).

Many studies failed to demonstrate typical and specific muscle abnormalities. Bioptic studies (27-29) revealed only non-specific signs of muscle pathology without pathognomonic flags of FM. Needle electromyography found minor and, again, nonspecific changes looking for pathological evidence of motor unit recruitment (no loss of motor units and no fiber degeneration) (30). Multichannel surface electromyography seems to be of some interest, giving original information about acute alteration of motor unit recruitment strategies and chronic modification of muscle fiber type distribution, number or size $(31,32)$. Muscle alteration that is clinically expressed as fatigue could be the peripheral aspect of a central alteration of the sensory-motor interaction.

Muscles in a patient with FM probably undergo a pathologic remodelling related to an altered suprasegmental control (33). Because of this, their function is incorrect and ineffective.

However, these results are not strictly related to fibromyalgic muscle; they have also been recorded, for example, in healthy, deconditioned elderly populations (34). 


\section{Stiffness}

In FM patients, stiffness, typically, is not only articular but also generalized (global stiffness) and is common; but unlike in rheumatoid arthritis, it is worse upon awakening and in the evening. The incidence of morning stiffness lasting more than fifteen minutes has been reported in as many as $83 \%$ of patients (35).

Morning stiffness does not correlate with severity of FM (19), but it does correlate with pain (36).

\section{Swollen feeling in tissue}

Swelling of the hands and feet is often present in FM and is sometimes accompanied by numbness and tingling. Generalized swelling may be present as the result of inactivity as well.

In many patients, the sensation of swelling is present (22), even if no objective joint swelling is present on physical examination. In some patients, the skin overlying a muscle with known myofascial pain syndrome can exhibit the characteristic orange peel skin; however, trophic edema does not "pit" upon digital pressure in these cases.

\section{NON-MUSCULOSKELETAL SYMPTOMS}

\section{Fatigue}

Fatigue is quite common in FM; it is generally worse in the morning and patients often awaken feeling more exhausted than when they went to bed. Moderate or severe fatigue occurs in about $75 \%$ to $90 \%$ of patients $(35,36)$. Patients will typically describe their fatigue using the expression, "I'm always tired." Other descriptors for fatigue include exhaustion, tiredness, lack of energy, and sometimes, a global feeling of general weakness. Fatigue in these patients seems to be unexpected or inappropriate with a delayed reactivity following physical exertion (next day or even later). After exercise FM patients can feel worse rather than better. Normal physical or intellectual exertion may take an inordinate amount of time to regain the preexertion level of function and competence. Fatigue may be generated by many different mechanisms. Arousal fatigue is a typical cause of fatigue in FM; it results from an inadequate quantity or quality of sleep or from some medications. Muscular fatigue is commonly seen in FM, and motivational fatigue is usually associated with depression, which is present in about $30 \%$ or more of FM patients (17). Fatigue is also associated with pain severity and functional disabilities (37).

\section{Sleep dysfunction}

Non restorative sleep is common in FM. About $75 \%$ of patients describe sleep disturbances that may include early, middle or late insomnia; hypersomnia; frequent awakening; light sleep with irregular diurnal rest; or reversed or chaotic sleep rhythms. Poor sleep may aggravate pain and may also contribute to disturbed sleep. There is a relationship, in fact, between poor sleep and pain, and sleep disturbances are important in the genesis of tender points $(37,38)$.

Loss of deeper phases of sleep (stages three and four) is characteristic of FM and leads to the loss of restorative feelings on awakening.

Polysomnographic studies have shown that, compared to controls, FM patients experience a reduced portion of deep sleep, REM sleep, and total sleep time, a greater number of awakenings and a significant pattern indicating the intrusion of alpha waves on delta rhythm (39).

Some researchers have suggested that alpha intrusion is an intrinsic characteristic of non-REM sleep in FM patients (40-42). Others, however, do not agree because this phenomenon may be observed in normal individuals and in patients with other chronic pain syndromes, such as rheumatoid arthritis and chronic fatigue syndrome $(41,43)$. Still other researchers have demonstrated a poor presence of alpha waves intrusion during deep sleep in FM patients $(44,45)$.

From these varied studies, a reasonable conclusion is that fragmented sleep is an important factor for the physiopathology of FM symptoms; and although an excess of alpha intrusion is not specific for FM, it may be considered a sensitive marker for non-restorative sleep nevertheless.

Restless legs syndrome or periodic limb movement disorder may also contribute to sleep disturbances. Restless legs syndrome has been reported in approximately $30 \%$ of FM patients compared to $2 \%$ of controls (24). Periodic limb movement disorder is another common sleep disturbance that affects about $30 \%$ of patients over the age of 50 . It is often independent of the presence of FM and is characterized by transient episodes ( 0.5 to 5 seconds) of partial bending of the ankles, knees, or hips (46). This disorder is common, but is not as significant in FM patients.

Sleep apnea syndrome and other breathing conditions, like periodic breathing during sleep, might be observed in FM patients. Sleep apnea syndrome is characterized by recurring episodes of upper breathing apparatus (mouth and nose) obstruction 
during sleep with significant ipopnea or apnea (47). About $2 \%$ of women and $44 \%$ of men with FM are affected by sleep apnea syndrome (48). In spite of this, apneas are unlikely culprits for FM symptoms (49).

\section{Paresthesia}

Paresthesia has been shown to appear in as many as $84 \%$ of FM patients (50) and occurs predominantly in the extremities. In some patients these symptoms can be quite severe but without sensory deficits on physical examination. This symptom is described as tingling, "pins and needles," or numbness. Paresthesia may have a radiating quality that mimics a neurologic disorder but without radicular distribution. Electromyographic and nerve conduction velocity studies are normal in these patients (50).

\section{ADDITIONAL CLINICAL SYMPTOMS}

The clinical presentation of FM may vary somewhat, and the additional symptoms, though not required for ACR criteria, are still clinically important (Table II).

\section{Neurologic manifestations}

FM patients often report symptoms that are neurological in nature. Muscle dysfunction often manifests as a hypertonic or hypotonic state, an abnormal twitch response, cramps, weakness and fasciculation. Headaches, temporomandibular joint disorder, perceptual disturbances, spatial and temporal instability and sensory overload phenomena often occur. In particular, the patient may be hypersensitive to light, sound, noise, speed, odours and other mixed sensory modalities. Perceptual disturbances may include dizziness, numbness, tinnitus, nausea or shooting pain (17).

\section{Neurocognitive manifestations}

Neurocognitive disturbances are usually present in FM patients. These include impaired concentration and short-term memory consolidation, reduced performance speed, inability to multi-task, distractibility and cognitive overload. Complaints of cognitive "fog" (fibro-fog) or simple confusion, linguistic performance impairment, dyslexia when fatigued, and difficulty with writing, reading, mathematics, word retrieval and speaking are especially common. It is easy for patients to lose track of things and to forget many things (17).
Table II - Symptoms in Fibromyalgia Syndrome Based on Several Large Series.

\begin{tabular}{|c|c|}
\hline Symptoms & Mean* \\
\hline \multicolumn{2}{|l|}{ Musculoskeletal } \\
\hline Pain at multiple sites & 100 \\
\hline Stiffness & 78 \\
\hline "Hurt all over" & 64 \\
\hline Swollen feeling in tissue & 47 \\
\hline \multicolumn{2}{|l|}{ Nonmusculoskeletal } \\
\hline General fatigue & 86 \\
\hline Morning fatigue & 78 \\
\hline Poor sleep & 65 \\
\hline Paresthesia & 54 \\
\hline \multicolumn{2}{|l|}{ Associated syndrome } \\
\hline Headaches & 53 \\
\hline Dysmenorrhea & 43 \\
\hline Irritable bowel syndrome & 40 \\
\hline Restless legs syndrome & 31 \\
\hline Sicca syndrome & 15 \\
\hline Raynaud's phenomenon & 13 \\
\hline Female urethral syndrome & 12 \\
\hline \multicolumn{2}{|c|}{$\begin{array}{l}\text { *Mean values derived from percentage figures reported in several studies. In Ra- } \\
\text { chlin ES e Rachlin IS Myofascial pain and fibromyalgia: trigger point management } \\
\text { (30). Modified from Yunus MB, Masi AT: Fibromyalgia, restless legs syndrome, } \\
\text { periodic limb movement disorder and psychogenic pain. In McCart DJ Jr, Koop- } \\
\text { man WJ (eds): Arthritis and Allied Conditions: A Textbook of Rheumatology, 12th } \\
\text { ed. Philadelphia, Lea \& Febiger, 1993, pp 1383-1405. }\end{array}$} \\
\hline
\end{tabular}

FM patients have cognitive function that is worse than that in age-matched controls (51) and similar to that in adults 20 years older with respect to longterm memory and working memory (i.e. the amount of information a person can store and process simultaneously) (52).

FM patients are able to perform at a similar level as healthy controls, but this is only due to more extensive neural activation in frontal and parietal brain regions (53). This supports the hypothesis that FM patients show an aging effect that requires increased use of cognitive resources to maintain comparable levels of performance as their sameaged peers.

The finding of an acceleration of age-related brain changes has been supported by the observation that FM patients had significantly less total gray matter volume and 3.3 times greater age-associated decrease in gray matter than healthy controls. The longer the individuals had had fibromyalgia, the greater the gray matter loss, with each year of fibromyalgia being equivalent to 9.5 times the loss in normal aging (54).

This is probably due to the mechanism of neurotoxicity (neuronal apoptosis). 
Autonomic and neuroendocrine manifestations

These manifestations indicate a general loss of internal homeostasis and adaptation. They include cardiac arrhythmias, hypotension, dizziness, sense of lightheadedness, vertigo, vasomotor instability, sicca syndrome, temperature instability, heat or cold intolerance, respiratory disturbances, intestinal and bladder motility disturbances, dysmenorrhea, loss of adaptability and tolerance for stress, emotional flattening, and reactive depression (17).

\section{Associated symptoms and conditions and central sensitivity syndrome}

Chronic headaches, irritable bowel, irritable bladder and female urethral syndromes, primary dys- menorrhea, restless legs syndrome, and sicca syndrome have been often described in FM, more common than in pain-free normal controls (3). But several other similar syndromes, including FM, are now considered to form a spectrum of illnesses with central sensitivity, described previously as CSS (15) (Table III).

\section{Psychiatric disorders and psychological factors}

Psychological factors are an important determinant of any form of pain including chronic pain, irrespective of the cause, and FM is no exception. Psychological distress perpetuates pain, and chronic pain may cause psychological disturbance.

Table III - Symptoms that may be present, not included as part of the criteria for diagnosis (17).

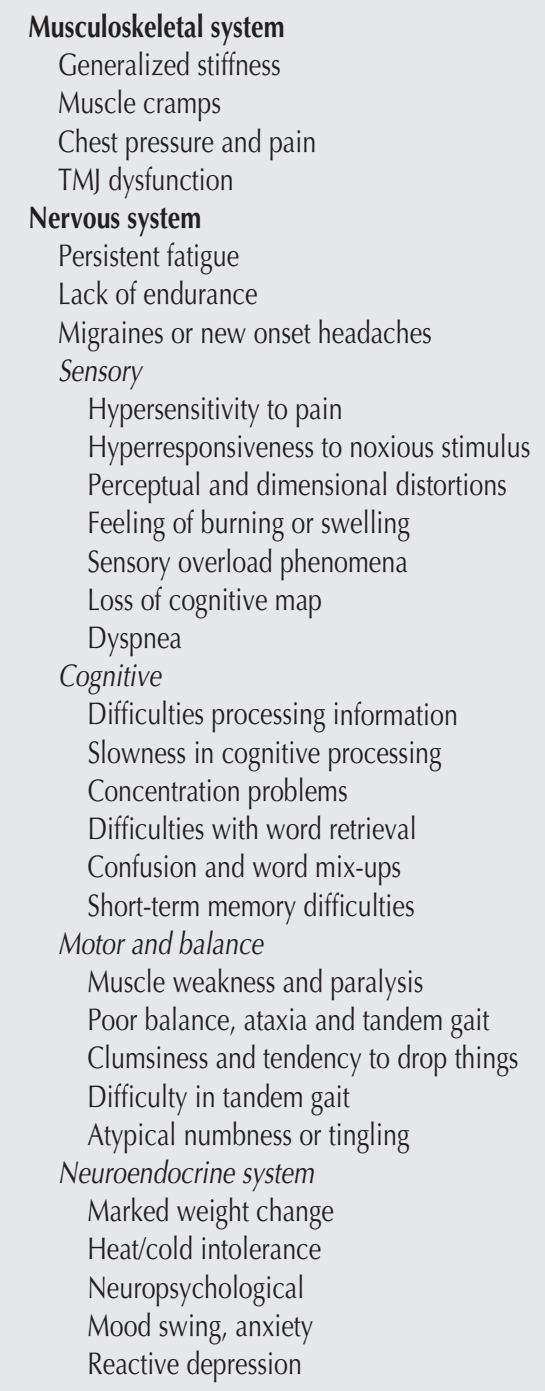

Visual and auditory disturbances

Visual changes or eye pain

Double, blurred and wavy vision

Dry or itchy eyes

Photophobia

Tinnitus-buzzing or ringing in ears

Hyperacusis and interference from background noise

Sleep disturbances

Sleep disorder, hyper or insomnia

Non-refreshing sleep

Circulatory system

Neurally-mediated hypotension

Fainting or vertigo

Palpitations and tachycardia

Fluid retention

Bruising

Digestive system

Lump in throat

Nausea

Heart burn

Abdominal pain

Irritable bowel syndrome

Urinary system

Irritable bladder

Overactive bladder

Reproductive syndrome

Dysmenorrhea

Pre-menstrual syndrome or irregular cycles

Loss of sexual libido or impotence

Anorgasmia 
A minority subgroup of patients $(30-40 \%)$ has a significant psychological disturbance (55).

Several studies provide evidence that psychiatric disorders occur at significantly higher rates in subjects with FM compared with other pain patients or healthy controls. Other studies contend that the frequency of such distress is similar to that in other chronic disease, such as rheumatoid arthritis (55). Studies examining psychiatric comorbidity in community samples of subjects with FM found elevated levels of psychopathology $(56,57)$, although psychiatric illness is not a necessary factor in the etiopathogenesis of FM.

Psychiatric disorders most commonly described are mood disorders.

Current major depression has been detected in 14$36 \%$ of patients with FM $(58,59)$ compared to 6.6 $\%$ of healthy subjects in a community sample (60). Family history studies indicate a higher prevalence of mood disorders in first degree relatives of patients with FM compared to first degree relatives of patients with rheumatoid arthritis and healthy controls $(61,62)$.

Subjects with FM report childhood traumatic experiences more frequently than medically ill or healthy controls; and they report a high prevalence of emotional neglect or abuse (48\%) and physical maltreatment (23\%) as well (63).

Job-related stress or or physical stressors may act as precipitating factors, but the impact of these stressors may only be realized if they have strong personal significance. An etiopathogenetic link between FM and life stress is also suggested by the comorbid occurrence of post-traumatic stress disorder.

Post-traumatic stress disorder symptoms were founded in $56 \%$ of patients with FM (64).

Research on personality traits in FM has yielded inconsistent results, but no personality disorders have been associated with FM (65).

Despite all of this, cognitive styles are increasingly being recognized as important factors in the experience of pain. For example, catastrophizing, which is characterized by pessimistic beliefs about oneself, others, and the future and by defining pain as awful and unbearable, is a common cognitive style that is known to modulate pain reports and pain-related disability. It seems to play a substantial role in the development of pain chronicity and in the experience of chronic pain and pain-related disability. It is an independent factor that is only partially associated with depression.

Catastrophizers hardly shift their attention away from painful or threatening stimuli, and they attach more threat or harm to non-painful stimuli than is warranted (66).

\section{THE SIGNS}

The most significant finding related to FM is the presence of multiple tender points (3). Tender points are best elicited by manual palpation, specifically by digital pressure using an approximate total force of four $\mathrm{Kg}$. A small subgroup of patients is diffusely tender all over. It is necessary to underline that the tender point never aches spontaneously.

Other physical signs, though not necessary for diagnosis, are skinfold tenderness, which is assessed by pinching a fold of skin and subcutaneous tissue on tender point sites, cutaneous hyperaemia at the tender point site after examination, and reticular discoloration (livedo reticularis) in the extremities.

Negative findings are the absence of joint swelling, a normal range of joint motion and muscle strength, and normal sensory function and reflexes (56).

\section{CONCLUSION}

FM is a chronic pain condition in which patients report not only widespread pain but also a variety of other complaints. The cardinal features are chronic widespread pain in the presence of multiple tender points throughout the body on physical examination. The ACR 1990 definition for clinical trials proposed compulsory criteria for classifying FM in adults and was not intended to be used for clinical diagnosis.

On the contrary, diagnosis is made by a combination of patient history, physical examination, laboratory evaluations, and exclusion of other causes for symptoms attributable to FM.

Three key features - pain, fatigue and sleep disturbance - are present in virtually every patient with FM. The hallmark symptom that differentiates FM from most other medical conditions is allodynia to even the mildest palpation or physical touch. The tender point, which never aches spontaneously, is the only cardinal sign, and it can be elicited by manual palpation via digital pressure.

FM symptoms can be summarized in musculoskeletal, non-musculoskeletal, and additional clinical symptoms. 
Associated symptoms and conditions must be considered in patient's evaluation because several associated illnesses are more common in FM patients than in the normal population.

The evolving idea of CSS, which is based on neuroendocrine aberrations interacting with psychosocial factors, will be an important new concept to consider in the daily diagnosis of FM and related conditions.

The Wolfe editorial entitled "Stop using the ACR Criteria in the Clinic" is a great article that will encourage physicians to obtain complete knowledge of all common and uncommon FM symptoms to minimize improper diagnosis.

\section{SUMMARY}

Fibromyalgia syndrome (FM) is a common chronic pain condition that affects at least $2 \%$ of the adult population. Chronic widespread pain is the defining feature of FM, but patients may also exhibit a range of other symptoms, including sleep disturbance, fatigue, irritable bowel syndrome, headaches, and mood disorders. The etiology of FM is not completely understood and the syndrome is influenced by factors such as stress, medical illness, and a variety of pain conditions. Establishing diagnosis may be difficult because of the multifaceted nature of the syndrome and overlap with other chronically painful conditions. A unifying hypothesis is that FM results from sensitization of the central nervous system; this new concept could justify the variety of characteristics of the syndrome. FM symptoms can be musculoskeletal, non-musculoskeletal, or a combination of both; and many patients will also experience a host of associated symptoms or conditions. The ACR classification criteria focus only on pain and disregard other important symptoms; but three key features, pain, fatigue and sleep disturbance, are present in virtually every patient with FM. Several other associated syndromes, including circulatory, nervous, digestive, urinary and reproductive systems are probably a part of the so called central sensitivity or sensitization syndrome. A minority subgroup of patients (30-40\%) has a significant psychological disturbance. Psychological factors are an important determinant of any type of pain, and psychological comorbidity is frequent in FM. Psychiatric disorders most commonly described are mood disorders, but psychiatric illness is not a necessary factor in the etiopathogenesis of FM.

Key words - Fibromyalgia, symptoms, sleep disorders, restless leg syndrome, chronic pain, fatigue.

Parole chiave - Fibromialgia, sintomi, disturbi del sonno, syndrome delle gambe senza riposo, dolore cronico, fatica.

\section{REFERENCES}

1. Clauw DJ. Elusive syndromes: treating the biologic basis of fibromyalgia and related syndromes. Cleve Clin J Med 2001; 68: 830, 832-4.

2. Bennett R. Fibromyalgia, chronic fatigue syndrome, and myofascial pain. Curr Opin Rheumatol 1998; 10: 95-103.

3. Wolfe F, Smythe HA, Yunus MB, et al. The American College of Rheumatology 1990 Criteria for the Classification of Fibromyalgia. Report of the Multicenter Criteria Committee. Arthritis Rheum 1990; 33: 160-72.

4. Crofford LJ, Clauw DJ. Fibromyalgia: where are we a decade after the American College of Rheumatology classification criteria were developed? Arthritis Rheum 2002; 46: 1136-8.

5. Aaron LA, Buchwald D. A review of the evidence for overlap among unexplained clinical conditions. Ann Intern Med 2001; 134: 868-81.

6. Schneider MJ, Brady DM, Perle SM. Commentary: differential diagnosis of fibromyalgia syndrome: proposal of a model and algorithm for patients presenting with the primary symptom of chronic widespread pain. J Manipulative Physiol Ther 2006; 29: 493-501.

7. Cöster L, Kendall S, Gerdle B, Henriksson C, Henriksson $\mathrm{KG}$, Bengtsson $\mathrm{A}$. Chronic widespread musculoskeletal pain - A comparison of those who meet cri- teria for fibromyalgia and those who do not. Eur J Pain 2008; 12: 600-10.

8. Fitzcharles MA, Boulos P. Inaccuracy in the diagnosis of fibromyalgia syndrome: analysis of referrals. Rheumatology (Oxford) 2003; 42: 263-7.

9. Wolfe F. Stop using the American College of Rheumatology criteria in the clinic. J Rheumatol 2003; 30: 1671-2.

10. Häuser W, Zimmer C, Felde E, Köllner V. What are the key symptoms of fibromyalgia?: Results of a survey of the German Fibromyalgia Association. Schmerz 2008; 22: 176-83.

11. Yunus MB, Masi AT, Aldag JC. Preliminary criteria for primary fibromyalgia syndrome (PFS): multivariate analysis of a consecutive series of PFS, other pain patients, and normal subjects. Clin Exp Rheumatol 1989; 7: 63-9.

12. Jacobsen S, Danneskiold-Samsoe B, Lund B. Consensus document on fibromyalgia: the Copenhagen declaration. J Musculoske Pain 1993; 1: 295-312.

13. Mease P, Arnold LM, Bennett R, et al. Fibromyalgia syndrome. J Rheumatol 2007; 34: 1415-25.

14. Yunus MB. Fibromyalgia and overlapping disorders: the unifying concept of central sensitivity syndromes. Semin Arthritis Rheum 2007; 36 (6): 339-56.

15. Yunus MB. Central Sensitivity Syndromes: A new paradigm and group nosology for fibromyalgia and over- 
lapping conditions, and the related issue of disease versus illness. Semin Arthritis Rheum. 2008 [Epub ahead of print].

16. Wolfe F, Hawley DJ, Cathey MA, Caro X, Russell IJ. Fibrositis: symptom frequency and criteria for diagnosis. An evaluation of 291 rheumatic disease patients and 58 normal individuals. J Rheumatol 1985; 12: 1159-63.

17. Jain KA, Carruthers M, Van De Sande MI, et al. Fibromyalgia Syndrome: Canadian clinical working Case Definition, diagnostic and treatment protocols - A consensus document. J Musculoske Pain 2004; V. 11: 3107.

18. Leavitt F, Katz RS, Golden HE, Glickman PB, Layfer LF. Comparison of pain properties in fibromyalgia patients and rheumatoid arthritis patients. Arthritis Rheum 1986; 29: 775-81.

19. Yunus MB, Masi AT, Aldag JC. A controlled study of primary fibromyalgia syndrome: clinical features and association with other functional syndromes. J Rheumatol Suppl 1989; 19: 62-71.

20. Pellegrino MJ. Atypical chest pain as an initial presentation of primary fibromyalgia. Arch Phys Med Rehabil 1990; 71: 526-8.

21. Reilly PA, Littlejohn GO. Peripheral arthralgic presentation of fibrositis/fibromyalgia syndrome. J Rheumatol 1992; 19: 281-3.

22. Campbell SM, Clark S, Tindall EA, Forehand ME, Bennett RM. Clinical characteristics of fibrositis. I. A "blinded," controlled study of symptoms and tender points. Arthritis Rheum 1983; 26: 817-24.

23. Moldofsky H. Chronobiological influences on fibromyalgia syndrome: theoretical and therapeutic implications. Baillieres Clin Rheumatol 1994; 8: 801-10.

24. Yunus MB, Aldag JC. Restless legs syndrome and leg cramps in fibromyalgia syndrome: a controlled study. BMJ 1996; 312: 1336-9.

25. Maquet D, Croisier JL, Renard C, Crielaard JM. Muscle performance in patients with fibromyalgia. Joint Bone Spine 2002; 69: 293-9.

26. Dombernowsky T, Dreyer L, Bartels EM, DanneskioldSamsøe B. Muscular strength in patients with fibromyalgia. A literature review. Ugeskr Laeger 2008; 170: 217-24.

27. Sprott H, Salemi S, Gay RE, et al. Increased DNA fragmentation and ultrastructural changes in fibromyalgic muscle fibres. Ann Rheum Dis 2004; 63: 245-51.

28. Gronemann ST, Ribel-Madsen S, Bartels EM, Danneskiold-Samsoe B, Bliddal H. Collagen and muscle pathology in fibromyalgia patients. Rheumatology (Oxford) 2004; 43: 27-31.

29. Takahashi M, Oikawa M, Nagano A. Effect of age and menopause on serum concentrations of pentosidine, an advanced glycation end product. J Gerontol A Biol Sci Med Sci 2000; 55: M137-40.

30. Zidar J, Bäckman E, Bengtsson A, Henriksson KG. Quantitative EMG and muscle tension in painful muscles in fibromyalgia. Pain 1990; 40: 249-54.

31. Casale R, Farina D, Merletti R, Rainoldi A. Myoelectric manifestations of fatigue during a twelve day ex- posure to hypobaric hypoxia. Muscle Nerve 2004; 30 : 618-35.

32. Rainoldi A, Casale R, Hodges P, Jull G. Applications in rehabilitation medicine and related fields. In: Merletti R, Parker P, editors. Electromyography Physiology, engineering and non invasive applications. Hoboken, New Jersey, USA: J. Wiley/IEEE Press Publication 2004; 403-33.

33. Casale R, Sarzi-Puttini P, Gazzoni M, Fundarò C, Rainoldi A. Central motor control failure in fibromyalgia: a surface electromyography study. E J Appl Phys (under review 2008).

34. Casale R, Rainoldi A, Nilsson J, Bellotti P. Can continuous physical training counteract aging effect on myoelectric fatigue? A surface electromyography study application. Arch Phys Med Rehabil 2003; 84: 513-7.

35. Lessard JA, Russell IJ: Fibrositis/fibromyalgia in private rheumatology practice; systematic analysis of a patient data base. 1989 (unpublished) Reported in: Fibrositis/fibromyalgia (Chapter 23), in The Clinical and Scientific Basis of Myalgia Encephalomyelitis/Chronic Fatigue. Syndrome. Editors: Hyde BM, Goldstein J, Levine P. The Nightingale Research Foundation, Ottawa, Canada, 1992.

36. Russell IJ: Fibrositis/fibromyalgia (Chapter 23), in The Clinical and Scientific Basis of Myalgia Encephalomyelitis/Chronic Fatigue. Syndrome. Editors: Hyde BM, Goldstein J, Levine P. The Nightingale Research Foundation, Ottawa, Canada, 1992.

37. Yunus MB, Inanici F, Aldag JC, Mangold RF. Fibromyalgia in men: comparison of clinical features with women. J Rheumatol 2000; 27: 485-90.

38. Moldofsky H, Scarisbrick P, England R, Smythe H. Musculosketal symptoms and non-REM sleep disturbance in patients with "fibrositis syndrome" and healthy subjects. Psychosom Med 1975; 37: 341-51.

39. Moldofsky H. The significance, assessment, and management of non-restorative sleep in fibromyalgia syndrome. CNS Spectr 2008; 13: 22-6.

40. Moldofsky H, Scarisbrick P. Induction of neurasthenic musculoskeletal pain syndrome by selective sleep stage deprivation. Psychosom Med 1976; 38: 35-44.

41. Branco J, Atalaia A, Paiva T. Sleep cycles and Alpha Delta Sleep in Fibromyalgia Syndrome. J Rheumatol 1994; 21: 1113-7.

42. Drewes AM,Nielsen KD,Taagholt SJ, Bjerregard K, Svendsen L, Gade J. Sleep intensity in fibromyalgia: focus on the microstructure of the sleep process. Br J Rheumatol 1995; 34: 629-35.

43. Roizenblatt S, Moldofsky H, Benedito-Silva AA, Tufik $\mathrm{S}$. Alpha sleep characteristics in fibromyalgia. Arthritis Rheum 2001; 44: 222-30.

44. Lentz MJ, Landis CA, Rothemel J, et al. Effect of selective slow wave alwwp diaruption on musculoskeletal pain and fatigue in middle aged women. J Rheumatol 1999; 26: 1586-92.

45. Sergi M, Rizzi M, Braghiroli A, et al. Periodic breathing during sleep in patients affected by fibromyalgia sindrome. Eur Resp J 1999; 14: 203-8. 
46. Coleman RM, Pollak CP, Weitzman ED. Periodic movement in sleep (nocturnal myoclonus): relation to sleep disorders. Ann Neurol 1980; 8: 416-21.

47. De Backer WA. Central sleep apnoea, pathogenesis and treatment: an overview and perspective. Eur Respir J 1995; 8: 1372-83.

48. May KP, West SG, Naker MR, Everett DW. Sleep apnea in male patients with the fibromyalgia syndrome. Am J Med 1993; 94: 505-8.

49. Lario BA, Teran J, Alonso JL, et al. Lack of association between fibromyalgia and sleep apnoea syndrome. Ann Rheum Dis 1992; 51: 108-11.

50. Simms RW, Goldenberg DL. Symptoms mimicking neurologic disorders in fibromyalgia syndrome. J Rheumatol 1988; 15: 1271-3.

51. Grace GM, Nielson WR, Hopkins M, Berg MA. Concentration and memory deficits in patients with fibromyalgia syndrome. J Clin Exp Neuropsychol 1999; 21: 477-87.

52. Park DC, Glass JM, Minear M, Crofford LJ. Cognitive function in fibromyalgia patients. Arthritis Rheum 2001; 44: 2125-213.

53. Bangert AS, Glass JM, Welsh RC, Crofford LJ, Taylor SF, Park DC. Functional magnetic resonance imaging of working memory in fibromyalgia. Arthritis Rheum 2003; 48: S90.

54. Kuchinad A, Schweinhardt P, Seminowicz DA, Wood PB Chizh BA, Bushnell MC. Accelerated brain gray matter loss in fibromyalgia patients: premature aging of the brain? J Neurosci 2007; 27: 404-7.

55. Rachlin ES, Rachlin IS. Myofascial Pain and Fibromyalgia, Trigger Point Management. $2^{\text {nd }}$ ed. St. Louis: Mosby, 2002.

56. Wolfe F, Ross K, Anderson J, Russell IJ. Aspects of fibromyalgia in the general population: sex, pain threshold, and fibromyalgia symptoms. J Rheumatol 1995; 22: 151-6.

57. White KP, Nielson WR, Harth M, Ostbye T, Speechley M. Chronic widespread musculoskeletal pain with or without fibromyalgia: psychological distress in a representative community adult sample. J Rheumatol 2002; 29: 588-94.

58. Buskila D, Cohen H. Comorbidity of fibromyalgia and psychiatric disorders. Curr Pain Headache Rep 2007; 11: 333-8.

59. Ahles TA, Khan SA, Yunus MB, Spiegel DA, Masi AT. Psychiatric status of patients with primary fibromyalgia, patients with rheumatoid arthritis, and subjects without pain: a blind comparison of DSM-III diagnoses. .Am J Psychiatry 1991; 148: 1721-6.

60. Kessler RC, Berglund P, Demler O, et al. The epidemiology of major depression: results from the National Comorbidity Survey Replication (NCS-R). JAMA 2003; 289: 3095-105.

61. Hudson JH, Arnold LM, Keck PE Jr, et al. Family study of fibromyalgia and affective spectrum disorders. Biol Psychiatry 2004; 56: 884-91.

62. Raphael KG, Janal MN, Nayak S et al. Familial aggregation of depression in fibromyalgia: a community - based test of alternate hypotheses. Pain 2004; 110: 449-60.

63. Van Houdenhove B, Neerinckx E, Lysens R et al. Victimization in chronic fatigue syndrome and fibromyalgia in tertiary care: a controlled study on prevalence and characteristics. Psychosomatics 2001; 42: 21-8.

64. Sherman JJ, Turk DC, Okifuji A. Prevalence and impact of posttraumatic stress disorder-like symptoms on patients with fibromyalgia syndrome. Clin J Pain 2000; 16: $127-34$.

65. Thieme K, Turk DC, Flor H. Comorbid depression and anxiety in fibromyalgia syndrome: relationship to somatic and psychosocial variables. Psychosom Med 2004; 66: 837-44.

66. Geisser ME, Casey KL, Brucksch CB, Ribbens CM, Appleton BB, Crofford LJ. Perception of noxious and innocuous heat stimulation among healthy women and women with fibromyalgia: association with mood, somatic focus, and catastrophizing. Pain 2003; 102: 243-50. 